\title{
RELAÇÕES HÍDRICAS EM DOIS HÍBRIDOS DE MILHO SOB DOIS CICLOS DE DEFICIÊNCIA HÍDRICA ${ }^{1}$
}

\author{
CARLOS PIMENTEL ${ }^{2}$
}

\begin{abstract}
RESUMO - Neste trabalho foram estudadas as relações hídricas de dois híbridos de milho (Zea mays L.), em casa de vegetação: o IAC 8222 (híbrido com tolerância ambiental) e o DINA 10 (híbrido comum); submetidos a um ou a dois ciclos de estresse, aos 30 e 46 DAP. O IAC 8222 manteve o potencial hídrico de folha $\left(\Psi_{\mathrm{hf}}\right)$ superior ao do DINA no primeiro ciclo de estresse e no segundo ciclo, em plantas que sofreram os dois ciclos (com endurecimento), no sexto e último dia de deficiência hídrica, não havendo diferenças em relação ao conteúdo hídrico relativo (CHR) entre os híbridos. Houve um aumento da concentração de açúcares solúveis e de aminoácidos com a deficiência hídrica, sem diferenças entre os híbridos no primeiro ciclo de déficit hídrico, e com aumento significativo somente na concentração de aminoácidos no DINA 10 submetido aos dois ciclos, no último dia do segundo ciclo. A concentração de $\mathrm{K}^{+}$não variou nem com os ciclos nem entre híbridos. Portanto, só houve diferenças na acumulação de solutos osmóticos entre os híbridos, quanto ao teor de aminoácidos no DINA 10 submetido aos dois ciclos, no segundo ciclo. Contudo, o IAC 8222 manteve o seu $\Psi_{\text {hf }}$ alto, podendo ter promovido um ajuste do coeficiente de extensibilidade de parede, que foi acentuado com o endurecimento.
\end{abstract}

Termos para indexação: Zea mays, potencial hídrico de folha, conteúdo hídrico relativo.

\section{WATER RELATIONS IN TWO HYBRIDS OF CORN UNDER TWO CYCLES OF WATER STRESS}

\begin{abstract}
A study was conducted to evaluate the water relations of two corn (Zea mays L.) hybrids in a greenhouse experiment: IAC 8222 (hybrid adapted to environmental stress) and DINA 10 (common hybrid), under one or two cycles of water stress applied at 30 and 46 days after sowing. During the first water deficit cycle, and at the second cycle for plants submitted to both cycles, the leaf water potential $\left(\Psi_{\mathrm{hf}}\right)$ of IAC 8222 was higher than the $\Psi_{\mathrm{hf}}$ of DINA 10, at the $6^{\text {th }}$ and last day of water stress, with no difference for the relative water content (CHR) between the hybrids. The soluble sugars and amino acids accumulated during the water stress, but no differences between the hybrids were observed on the first cycle, and it was showed a difference on amino acids concentration for DINA 10 with hardening, on the $6^{\text {th }}$ and last day of the second cycle. The $\mathrm{K}^{+}$concentration did not change neither during the water stress nor between the hybrids. These results showed only differences on the capacity of solute accumulation of DINA 10, for amino acids on the second water stress cycle. However, IAC 8222 maintained a higher $\Psi_{\text {hf }}$ accentuated by the hardening. This response can be due to an adjustment in the coefficient of cell wall extensibility
\end{abstract}

Index terms: Zea mays, leaf water potential, relative water content.

\section{INTRODUÇÃO}

A deficiência hídrica é considerada a maior causa de redução na produtividade agrícola em clima

\footnotetext{
${ }^{1}$ Aceito para publicação em 7 de janeiro de 1999.

${ }^{2}$ Eng. Agr., Dr., Prof. Titular, Dep. de Fitotecnia, IA UFRRJ, CEP 23851-970 Seropédica, RJ. E-mail: greenman@amcham.com.br
}

tropical. Porém, como existe uma variabilidade na adaptação à seca entre espécies e dentro da espécie, deve-se avaliar o comportamento de diferentes materiais genéticos, em condições de seca, para a recomendação de cultivo (Blum, 1997). Com o milho na região tropical verifica-se que $95 \%$ do cultivo são feitos em áreas sujeitas a um déficit hídrico, que causa uma queda de $10 \%$ a $50 \%$ da produção, em $80 \%$ da área cultivada (Bolaños \& Edmeades, 1995). 
Um dos mecanismos de adaptação à seca no milho é o acúmulo de solutos osmoticamente ativos na célula, em relação às plantas bem hidratadas. Tal fenômeno, chamado de ajustamento osmótico, permite a manutenção da turgescência, crescimento e fotossíntese, sob baixos valores de potencial hídrico de folha (Morgan, 1984). Já se conhecem, segundo Bray (1993), dois genes induzidos pela seca que podem estar envolvidos no ajustamento osmótico.

Contudo, Munns (1988) afirma que o ajustamento osmótico por si só não promove o crescimento, pois a turgescência gerada com o ajuste osmótico, não é o único fator de controle do crescimento. $\mathrm{O}$ crescimento é dependente da turgescência celular, mas também depende do módulo de elasticidade de parede celular e, conseqüentemente, do coeficiente de elasticidade desta. O ajustamento osmótico vai promover o turgor necessário para o crescimento, mas se não houver um ajustamento da parede celular, aumentando a sua capacidade de extensão, não haverá crescimento. $\mathrm{O}$ crescimento $(\mathrm{C})$, considerado um aumento irreversível do volume celular, é, portanto, determinado pela equação de Lockhart:

$\mathrm{C}=\mathrm{m} \times(\mathrm{P}-\mathrm{Y})$,

onde $\mathrm{m}$ é o coeficiente de extensibilidade de parede celular, P é o potencial de turgescência atual da célula, e Y é o potencial de turgescência mínimo requerido, para iniciar a expansão irreversível da parede celular (Poljakoff-Mayber \& Lerner, 1994).

O coeficiente de extensibilidade de parede é afetado pelo estresse hídrico, pela ação de enzimas, causando mudanças na composição da membrana e da parede celular e, conseqüentemente, na sua extensibilidade. Como a turgescência é a reação à tensão de parede, a extensibilidade desta vai controlar o potencial de turgescência e o potencial hídrico celular. Por isto, o crescimento é mais dependente da capacidade de extensão da parede que do turgor (Neumann, 1995). Provavelmente, o enrijecimento da parede de células de folhas em desenvolvimento pode representar o mecanismo de ajuste primário ao déficit hídrico, precedendo o lento ajuste osmótico, via acumulação ativa de solutos (Munns, 1988). Segundo Frensch \& Hsiao (1995), plantas de milho tolerantes à seca podem reduzir o potencial de turgescência mínimo (Y), mediante alterações na parede, para manter o crescimento de raízes sob deficiência hídrica.

Portanto, em plantas que fazem o ajustamento osmótico, mas primeiramente promovem um ajustamento da extensibilidade de parede, o potencial hídrico foliar poderá manter-se menos negativo, mas sobretudo o conteúdo hídrico relativo será menos reduzido. Além disso, o fenômeno conhecido como endurecimento permite ao vegetal maior ajustamento osmótico, quando este já tenha sido submetido a um primeiro ciclo de estresse hídrico. Os solutos acumulados no primeiro déficit hídrico não são prontamente assimilados e permitirão maior acúmulo e ajuste osmótico no segundo ciclo (Kramer \& Boyer, 1995). De acordo com Turner \& Jones (1980), os açúcares solúveis, aminoácidos e o $\mathrm{K}^{+}$equivalem de $60 \%$ a $100 \%$ dos compostos participantes do ajuste osmótico.

O objetivo deste trabalho foi estudar a resposta do conteúdo hídrico relativo e do potencial hídrico de folha, e dos teores de açúcares solúveis, de aminoácidos e de $\mathrm{K}^{+}$, em materiais contrastantes de milho, durante um ou dois ciclos de estresse hídrico.

\section{MATERIAL E MÉTODOS}

Os experimentos foram conduzidos em casa de vegetação, usando potes com $10 \mathrm{~kg}$ de terra do horizonte B de um solo Podzólico Vermelho-Amarelo (com maior teor de argila, promovendo portanto um dessecamento mais gradual do solo). No pote, foi feita uma adubação equivalente a $120 \mathrm{~kg} \mathrm{ha}^{-1} \mathrm{de} \mathrm{N}, 40 \mathrm{~kg} \mathrm{ha}^{-1}$ de $\mathrm{K}_{2} \mathrm{O}, 100 \mathrm{~kg} \mathrm{ha}^{-1} \mathrm{de}_{2} \mathrm{O}_{5}$ e $2000 \mathrm{~kg} \mathrm{ha}^{-1}$ de calcário dolomítico. Durante o experimento, as temperaturas médias oscilaram entre $28^{\circ} \mathrm{C}$ e $43^{\circ} \mathrm{C}$ e a umidade relativa do ar variou entre $55 \%$ e $70 \%$.

Foram utilizados dois híbridos comerciais de milho: o IAC 8222, selecionado para resistência ambiental, que sob condições de deficiência hídrica produz mais que os híbridos comuns, sendo considerado tolerante à seca (Miranda et al., 1984); e o DINA 10, produzido pela Dinamilho S.A., que é um híbrido comum de grande porte e alta produção quando irrigado, mas com drástica redução da produtividade sob déficit hídrico, e portanto sensível à seca.

Os dois ciclos de estresse, por suspensão da irrigação, foram impostos aos 30 dias após o plantio (DAP) e $46 \mathrm{DAP}$, por um período de seis dias até que o potencial hídrico do solo $\left(\Psi_{\mathrm{hs}}\right)$ atingisse valores em torno de 
-1,5 MPa (Fig. 1). O delineamento experimental foi um fatorial completamente casualizado, com 72 potes ( 2 híbridos $\mathrm{x} 3$ tratamentos (plantas submetidas somente ao primeiro ciclo de estresse; plantas submetidas somente ao segundo ciclo de estresse; e plantas submetidas aos dois ciclos de estresse, e portanto com endurecimento) $\mathrm{x} 4$ coletas (de 2 em 2 dias, durante os 6 dias de estresse) x 3 repetições).

Durante a deficiência hídrica, em cada ciclo de estresse, fez-se, entre as $7 \mathrm{~h}$ e $9 \mathrm{~h}$ da manhã em intervalos de dois dias: a) medidas do conteúdo hídrico relativo nas folhas (CHR), pelo método de Barrs \& Weatherley (1962); b) medidas do potencial hídrico de folha $\left(\Psi_{\mathrm{hf}}\right)$, com um psicrômetro (C-52 da Wescor; USA), acoplado a um microvoltímetro a ponto de orvalho (modelo HR-33T, da Wescor); c) coletas de $1 \mathrm{~g}$ de massa fresca da folha mais jovem com máxima expansão foliar, em cada pote. As amostras de folha foram conservadas em $20 \mathrm{~mL}$ de etanol $80 \%$, para as dosagens dos solutos osmoticamente ativos solúveis em álcool. No extrato obtido depois da trituração e filtragem dessas amostras, foram determinados: os teores de carboidratos solúveis totais, segundo a técnica descrita por Yemm \& Willis (1954); os teores de aminoácidos livres totais, pelo método de Yemm \& Cocking (1955); e os teores do íon inorgânico $\mathrm{K}^{+}$, por espectrofotometria de chama (Premachandra et al., 1991).

A partir das medições do $\mathrm{CHR}$ e do $\Psi_{\mathrm{hf}}$, foi estabelecida a curva de perda de umidade na folha, que é a relação entre o CHR e o $\Psi_{\mathrm{hf}}$, segundo Jones \& Turner (1978). A análise dessa relação permite verificar se o vegetal mantém o seu CHR alto, mediante o abaixamento do potencial

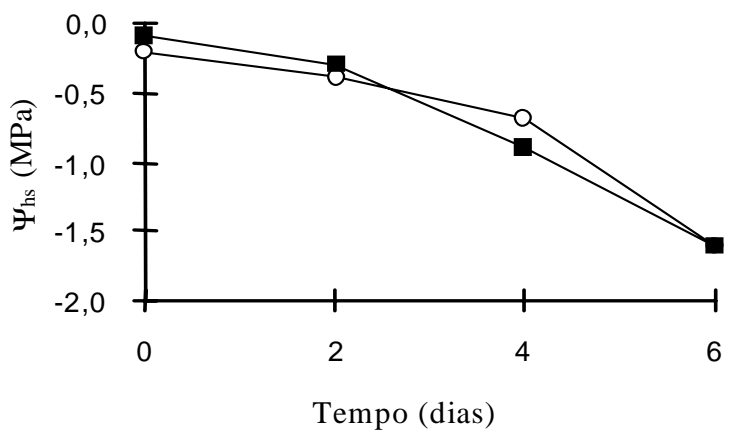

FIG. 1. Potencial hídrico do solo $\left(\Psi_{\mathrm{hs}}\right)$, durante o tratamento de déficit hídrico (média de seis repetições): (0) primeiro ciclo de deficiência hídrica, aplicado aos 30 dias após o plantio; (a) segundo ciclo de deficiência hídrica, aplicado aos 46 dias após o plantio. osmótico e, conseqüentemente, do $\Psi_{\mathrm{hf}}$, pelo ajuste osmótico, ou pela manutenção do $\Psi_{\mathrm{hf}}$ alto, pelo ajuste da elasticidade de parede. Ambos os mecanismos de adaptação à seca têm como objetivo a manutenção do CHR alto, que permite manter a atividade fisiológica do tecido (Neumann, 1995). No 2 o ciclo de estresse, as plantas submetidas a um primeiro ciclo, chamadas de plantas com endurecimento, já tiveram um ajuste da extensibilidade de parede e/ou um ajuste osmótico no primeiro estresse e, quando submetidas ao segundo déficit hídrico, terão uma maior tolerância ao dessecamento (Kramer \& Boyer, 1995).

No período de estresse foram medidos também às $9 \mathrm{~h}$, de dois em dois dias, o potencial hídrico do solo $\left(\Psi_{\mathrm{hs}}\right)$ (Fig. 1) e a temperatura do solo (Fig. 2), com psicrômetros (PT-55, da Wescor) acoplados ao mesmo microvoltímetro a ponto de orvalho (HR-33T, da Wescor), e localizado a $0,15 \mathrm{~m}$ de profundidade, no centro do pote. A temperatu-
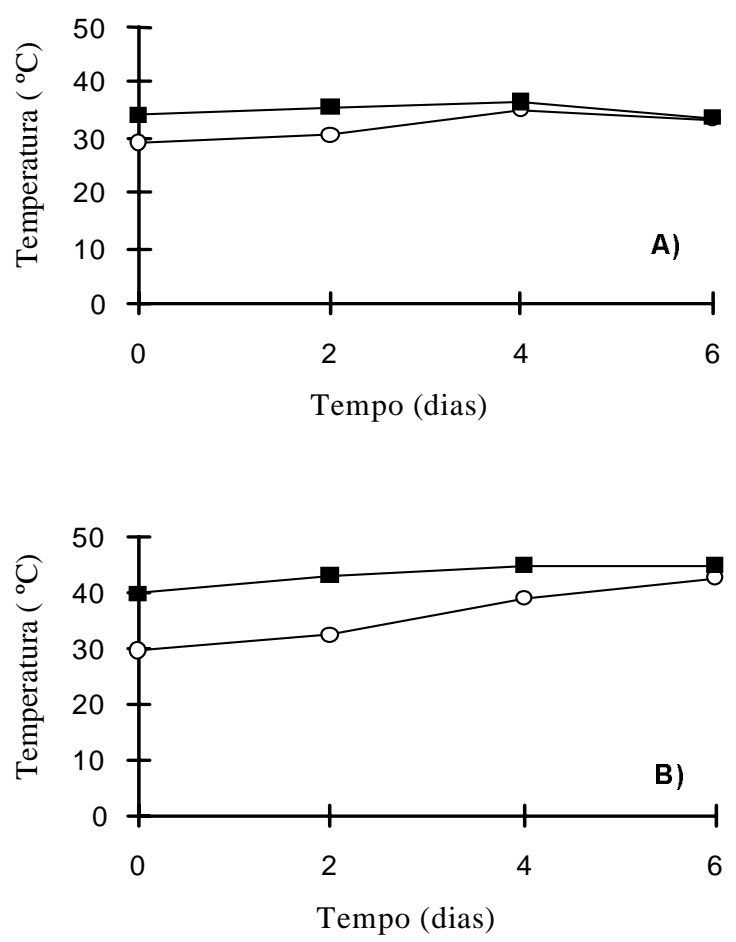

FIG. 2. Temperatura do solo (O) e do ar (口), durante o tratamento de déficit hídrico: A) primeiro ciclo de deficiência hídrica, aplicado aos 30 dias após o plantio; B) segundo ciclo de deficiência hídrica, aplicado aos 46 dias após o plantio.

Pesq. agropec. bras., Brasília, v.34, n.11, p.2021-2027, nov. 1999 
ra do ar (Fig. 2) foi obtida em um termoigrógrafo, no mesmo horário.

A análise de variância foi feita pelo teste $\mathrm{F}$ e, quando detectada significância, foi feita a comparação das médias pelo teste de Tukey a 5\%.

\section{RESULTADOS E DISCUSSÃO}

A temperatura do solo na capacidade de campo (dia 0 de estresse) era de $5^{\circ} \mathrm{C}$ e de $10^{\circ} \mathrm{C}$ inferior à temperatura do ar nos primeiro (Fig. 2A) e segundo experimentos (Fig. 2B), respectivamente. Com a secagem, a temperatura do solo se aproximou da do ar, nos dois ciclos de déficit hídrico. Tais resultados mostram que o vegetal submetido a uma deficiência hídrica, sob altas temperaturas do ar, sofrerá também um estresse térmico, pelo aumento da temperatura do solo, que poderá afetar o metabolismo do sistema radicular.

Durante os dois ciclos de estresse hídrico, a análise da relação entre o CHR e o $\Psi_{\mathrm{hf}}$, na chamada de curva de perda de umidade, associada aos acúmulos de solutos, permite avaliar a extensão dos mecanismos de adaptação à seca, por ajuste da extensibilidade de parede ou por ajustamento osmótico (Kramer \& Boyer, 1995).

No primeiro ciclo de estresse, o híbrido IAC 8222 manteve seu $\Psi_{\mathrm{hf}}$ significativamente superior ao do DINA 10, somente no sexto e último dia de déficit hídrico (Fig. 3). Para o CHR não houve diferença entre os híbridos sob estresse, porém houve uma redução significativa do CHR durante os dias de deficiência hídrica, para os dois híbridos (Fig. 3).

No primeiro ciclo de deficiência hídrica houve aumento gradativo no teor de carboidratos solúveis, apesar de não ter ocorrido diferença significativa entre os híbridos (Fig. 4A). O aumento do teor de carboidratos solúveis se dá no início do estresse hídrico, por causa da paralisação do crescimento, com certa manutenção da atividade fotossintética e, com a severidade do déficit hídrico, devido à hidrólise de amido (McCree et al., 1984; Pimentel $\&$ Rossiello, 1995). No que se refere ao acúmulo de aminoácidos livres (Fig. 4B), também não houve diferença significativa entre os híbridos, mas houve entre os dias uma acumulação significativa de aminoácidos solúveis, como já apresentado por Rossiello et al. (1981), em três cultivares de mi- 1ho. O acúmulo acentuado de aminoácidos, sobretudo sob déficit severo, ocorre pela paralisação do crescimento e da síntese de proteínas, associado à hidrólise destas (Turner \& Jones, 1980; Hanson \& Hitz, 1982). Em relação ao acúmulo de $\mathrm{K}^{+}$(Fig. 4C), não houve variações nos teores deste íon nem entre híbridos nem entre dias de estresse, mostrando que não houve aumento na absorção ou redistribuição de $\mathrm{K}^{+}$, em plantas estressadas. Porém Premachandra et al. (1991), mostraram que plantas bem supridas em $\mathrm{K}^{+}$, comparadas àquelas com baixa disponibilidade de $\mathrm{K}^{+}$, apresentam, sob deficiência hídrica, maior estabilidade membranar.

No segundo ciclo de estresse, foram estudadas as mesmas variáveis nos dois híbridos, em plantas que já haviam sofrido o primeiro ciclo de estresse, chamadas de plantas com endurecimento, e em plantas que não sofreram o primeiro estresse hídrico. Verificou-se que só houve diferença significativa quanto ao $\Psi_{\mathrm{hf}}$ do híbrido IAC 8222 com endurecimento, que manteve-se superior aos dos outros tratamentos, no sexto e último dia de estresse (Fig. 5). Em relação ao CHR dos híbridos, nos dois tratamentos, não houve diferenças significativas entre estes em cada dia de estresse. Houve diferenças somente entre os dias de estresse, mostrando uma redução significativa do $\mathrm{CHR}$, com a imposição da deficiência hídrica.

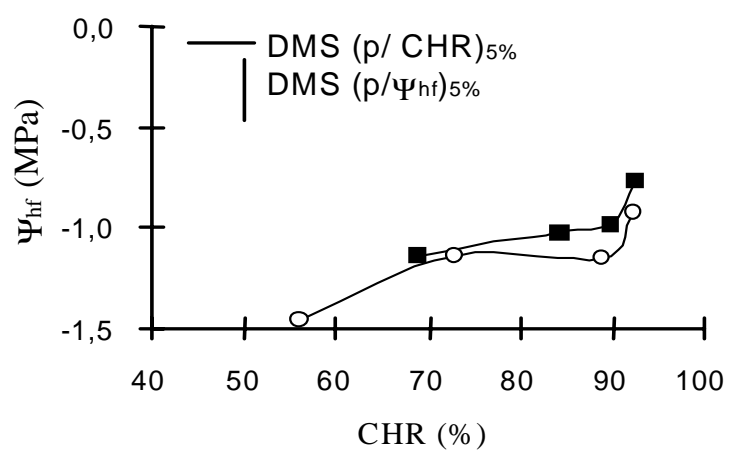

FIG. 3. Curva de perda de umidade da folha, a relação entre o potencial hídrico de folha $\left(\Psi_{\mathrm{hf}}\right)$ e o conteúdo hídrico relativo (CHR), em dois híbridos de milho, sob deficiência hídrica aplicada aos 30 dias após o plantio: (ש) IAC 8222 e (O) DINA 10. 
Os teores de açúcares solúveis totais (Fig. 6A) no segundo estresse hídrico aos 46 DAP, em plantas no dia 0 de estresse, foram quase o dobro dos valores de plantas hidratadas com $30 \mathrm{DAP}$, mesmo naquelas que sofreram somente o segundo ciclo de
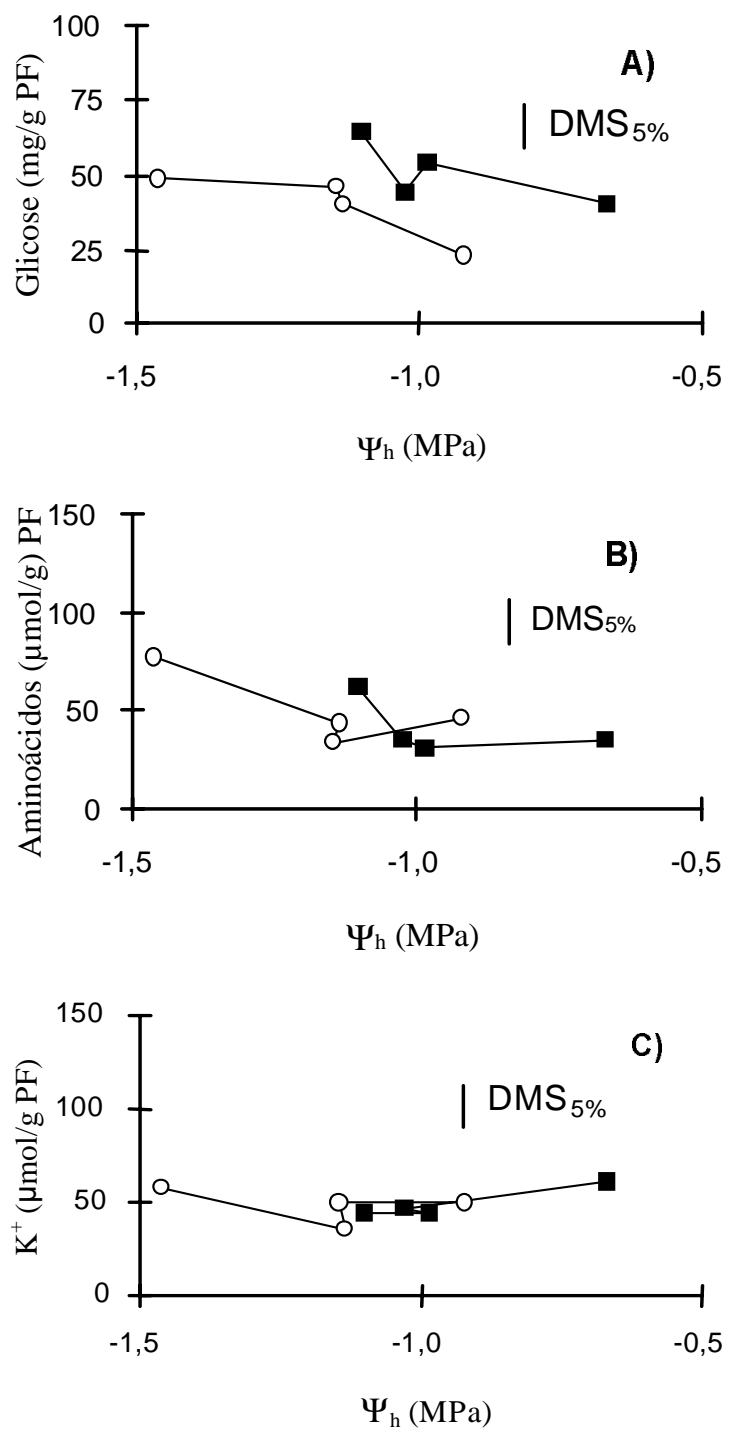

FIG. 4. Concentrações dos principais solutos osmoticamente ativos da folha, em dois híbridos de milho, sob deficiência hídrica aplicada aos 30 dias após o plantio: A) teores de açúcares solúveis; B) teores de aminoácidos livres; C) teores de $\mathrm{K}^{+}$; (口) IAC 8222 e (O) DINA 10. deficiência hídrica. Esse maior acúmulo de açúcares deve ser causado pela aproximação da fase reprodutiva da planta, quando a planta necessitará de tais reservas (Kramer \& Boyer, 1995). Contudo, não houve diferenças entre híbridos quanto à acumulação dos solutos. Em relação aos teores de aminoácidos livres (Fig. 6B), houve um aumento significativo no final do estresse, quando comparados com os teores das plantas controle (0 dia de estresse). Esse aumento foi superior ao ocorrido nas plantas de 30 DAP. Também foi verificado maior acumulação de aminoácidos livres no híbrido DINA 10 com endurecimento, comparado ao IAC 8222, também com endurecimento. Para os dois híbridos sem endurecimento, não houve diferenças. Tal aumento no acúmulo de aminoácidos livres pode ser causado pelo aumento da hidrólise de proteínas, em virtude das altas temperaturas (acima de $40^{\circ} \mathrm{C}$ ) durante esse ciclo (Fig. 2B). No que se refere aos teores de $\mathrm{K}^{+}$(Fig. 6C), da mesma forma que em plantas com $30 \mathrm{DAP}$, não houve variações nesses teores devido aos tratamentos ou à imposição do estresse.

Avaliando-se os resultados da relação $\Psi_{\mathrm{hf}} \mathrm{xCHR}$, associados com os resultados obtidos para os

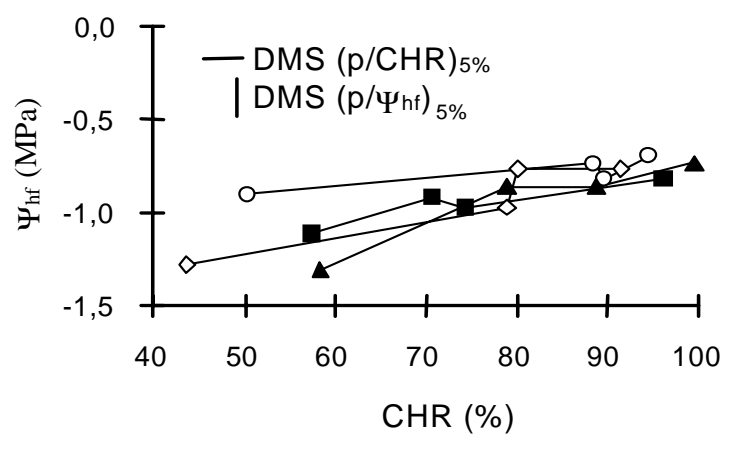

FIG. 5. Curva de perda de umidade da folha, a relação entre o potencial hídrico de folha $\left(\Psi_{\mathrm{hf}}\right)$ e o conteúdo hídrico relativo (CHR), em dois híbridos de milho, sob deficiência hídrica aplicada aos 46 dias após o plantio (DAP). (a) IAC 8222, com um ciclo de estresse aos 46 DAP; (O) IAC 8222, com dois ciclos de

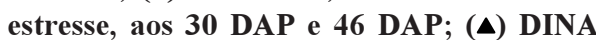
10, com um ciclo de estresse aos 46 DAP; $(\diamond)$ DINA 10, com dois ciclos de estresse, aos 30 DAP e 46 DAP. 

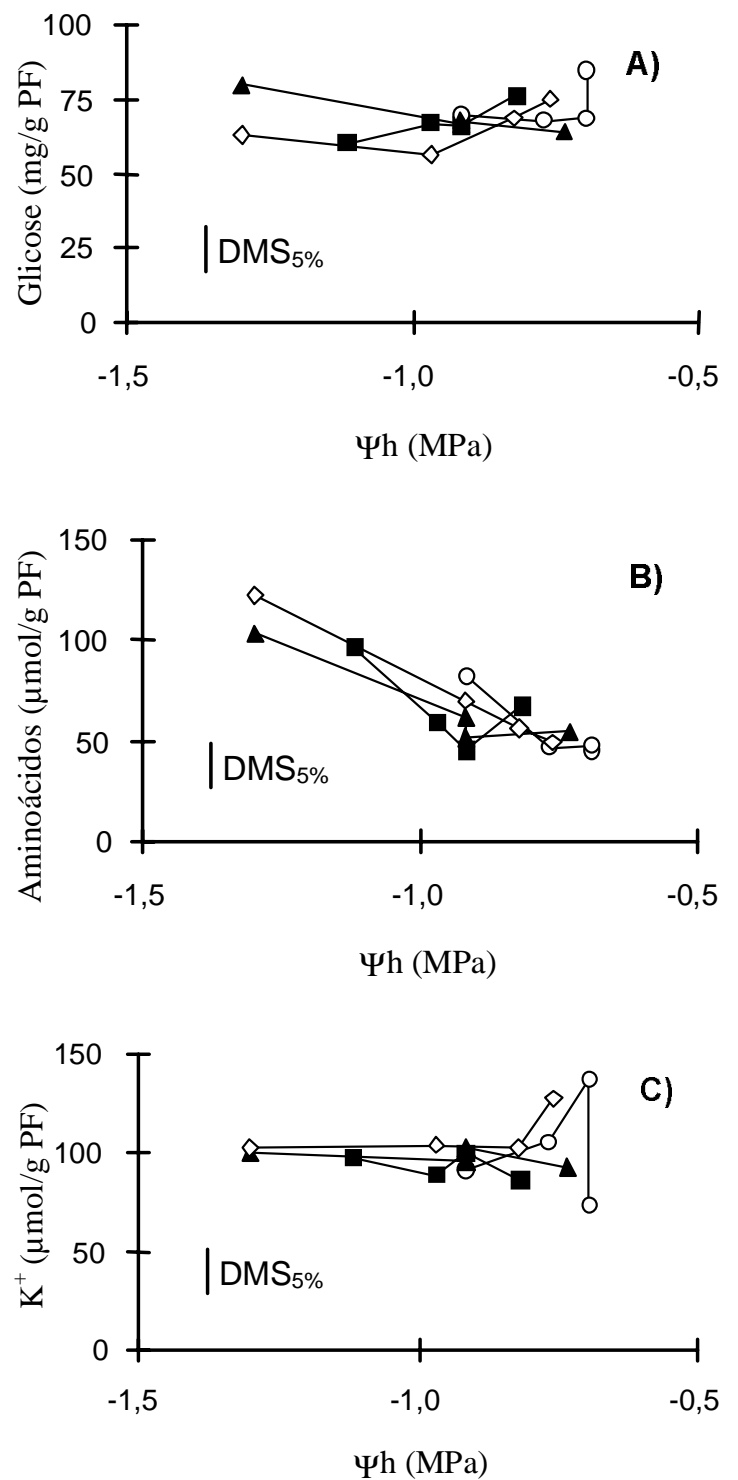

FIG. 6. Concentrações dos principais solutos osmoticamente ativos da folha, em dois híbridos de milho, sob deficiência hídrica aplicada aos 46 dias após o plantio (DAP): A) teores de açúcares solúveis; B) teores de aminoácidos livres; C) teores de $\mathrm{K}^{+}$; (ש) IAC 8222, com um ciclo de estresse aos 46 DAP; (O) IAC 8222, com dois ciclos de

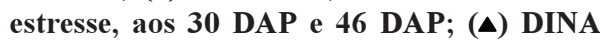
10, com um ciclo de estresse aos 46 DAP; $(\diamond)$ DINA 10, com dois ciclos de estresse, aos 30 DAP e 46 DAP. teores dos principais solutos osmoticamente ativos, pode-se destacar que a variação de resposta do híbrido IAC 8222 com endurecimento, principalmente em relação ao $\Psi_{\mathrm{hf}}$, não foi causada pela maior acumulação desses solutos, pois o IAC 8222 acumulou menores teores de aminoácidos do que o DINA 10 com endurecimento (Fig. 6B). Comparando os valores do $\Psi_{\mathrm{hf}}$ em relação ao pré-condicionamento do híbrido IAC 8222, nota-se que as plantas do IAC 8222 com endurecimento mantiveram esses valores superiores ao das outras plantas, no sexto dia (Fig. 5).

Os dados estão de acordo com os resultados de Ackerson (1983), que ao trabalhar com dois híbridos de milho mostrou que aquele com maior atividade fotossintética durante a deficiência hídrica apresentava valores de $\Psi_{\mathrm{hf}}$ superiores ao do mais sensível. O híbrido mais tolerante apresentou também maiores teores de açúcares e ácido abscísico. O que leva a concluir que provavelmente esse material mais tolerante, com alto $\Psi_{\mathrm{hf},}$, promoveu primeiro um ajustamento da extensibilidade de parede e, em seguida, o ajustamento osmótico. Tal variação no coeficiente de extensibilidade de parede, associado à acumulação de solutos, pelo ajuste osmótico, também foi demonstrado por Jones \& Turner (1978), com cultivares de sorgo, que apresentaram diferenças nas relações $\Psi_{\mathrm{hf}} \mathrm{xCHR}$ das cultivares.

Por isso, a avaliação do ajustamento osmótico, como parâmetro de tolerância à seca para o melhoramento vegetal, não se correlaciona com a produtividade do milho, sob deficiência hídrica (Bolaños $\&$ Edmeades, 1995), provavelmente porque o principal mecanismo de adaptação seja no nível da composição de parede e do seu ajuste de extensibilidade. As plantas de milho mais produtivas sob seca (Miranda et al., 1984) provavelmente fazem um ajuste de parede antes do ajuste osmótico.

\section{CONCLUSÕES}

1. A avaliação da relação entre o CHR e o $\Psi_{\mathrm{hf}}$, durante o abaixamento do $\Psi_{\mathrm{hs}}$, é o melhor indicador da resposta dos híbridos, sob déficit hídrico.

2. O monitoramento dos teores de solutos osmoticamente ativos nas folhas não é bom indica- 
dor de diferenças na resposta dos híbridos à deficiência hídrica.

3. O principal mecanismo fisiológico de adaptação à seca empregado pelo IAC 8222 é o ajuste da extensibilidade de parede celular, e o endurecimento permite maior ajuste.

\section{REFERÊNCIAS}

ACKERSON, R.C. Comparative physiology and water relations of two corn hybrids during water stress. Crop Science, Madison, v.23, p.278-283, 1983.

BARRS, H.D.; WEATHERLEY, P.E. A re-examination of the relative turgidity technique for estimating water deficits in leaves. Australian Journal of Biological Science, Melbourne, v.15, p.413-428, 1962.

BLUM, A. Crop responses to drought and the interpretation of adaptation. In: BELHASSEN, E. (Ed.). Drought tolerance in higher plants. Genetical, physiological and molecular biological analysis. Dordrecht: Kluwer Academic, 1997. p.57-70.

BOLAÑOS, J.; EDMEADES, G.O. Maize breeding for drought tolerance. In: INTERNATIONAL SYMPOSIUM ON ENVIRONMENTAL STRESS, 1992, Belo Horizonte. Maize in perspective: proceedings. Sete Lagoas: Embrapa-CNPMS / Ciudad del México: CIMMYT/UNDP, 1995. p.397431.

BRAY, E.A. Update on water déficit. Molecular responses to water deficit. Plant Physiology, Bethesda, v.103, p.1035-1040, 1993

FRENSCH, J.; HSIAO, T.C. Rapid response of the yield threshold and turgor regulation during adjustment of root growth to water stress in Zea mays. Plant Physiology, Bethesda, v.108, p.303-312, 1995.

HANSON, A.D.; HITZ, W.D. Metabolic responses of mesophytes to plant water deficits. Annual Review of Plant Physiology, Bethesda, v.33, p.163-203, 1982.

JONES, M.M.; TURNER, N.C. Osmotic Adjustment in leaves of Sorghum in response to water deficits. Plant Physiology, Bethesda, v.61, p.122-126, 1978.

KRAMER, P.J.; BOYER, J.S. Water relations of plants and soils. San Diego: Academic, 1995. 495p.

McCREE, K.J.; KALLESEN, C.E.; RICHARDSON S.G. Carbon balance of Sorghum plants during osmotic adjustment to water stress. Plant Physiology, Bethesda, v.76, p.898-902, 1984.
MIRANDA, L.T.; MIRANDA, L.E.C.; SAWAZAKI, E. Genética ecológica e melhoramento de milho. Campinas: Fundação Cargill, 1984.30p.

MORGAN, J.M. Osmoregulation and water stress in higher plants. Annual Review of Plant Physiology, Bethesda, v.35, p.299-319, 1984.

MUNNS, R. Why measure osmotic adjustment? Australian Journal of Plant Physiology, Melbourne, v. 15, p.717$726,1988$.

NEUMANN, P.M. The role of cell wall adjustment in plant resistance to water deficits. Crop Science, Madison, v.35, p.1258-1266, 1995.

PIMENTEL, C.; ROSSIELLO, R.O.P. Entendimentos sobre relações hídricas na cultura do milho. In: INTERNATIONAL SYMPOSIUM ON ENVIRONMENTAL STRESS, 1992, Belo Horizonte. Maize in perspective: proceedings. Sete Lagoas: Embrapa/CNPMS. Ciudad del México: CIMMYT/UNDP, 1995. p.131-146.

POLJAKOFF-MAYBER, A.; LERNER, H.R. Plants in saline environments. In: PESSARAKLI, M. (Ed.). Handbook of plant and crop stress. New York: Marcel Dekker, 1994. p.65-96.

PREMACHANDRA, G.S.; SANEOKA, H.; OGATA, S Cell membrane stability and leaf water relations as affected by potassium nutrition of water-stressed maize. Journal of Experimental Botany, London, v.42, p.739-745, 1991.

ROSSIELLO, R.P.; FERNANDES, M.S.; MAZUR, N. Effectos del dessecamento del suelo sobre el metabolismo de nitrogenio em tres cultivares de maiz (Zea mays L.). Turrialba, San José, v.31, p.227-235, 1981.

TURNER, N.C.; JONES, M.M. Turgor maintenance by osmotic adjustment: a review and evaluation. In: TURNER, N.C.; KRAMER, P.J. Adaptation of plants to water and higher temperature stress. New York: J. Wiley, 1980. p.87-103.

YEMM, E.W.; COCKING, E.C. The determination of amino acids with Ninhydrin. Analyst, London, v.80, p.209-213, 1955.

YEMM, E.W.; WILLIS, A.J. The estimation of carbohydrates in plant extracts by Antrone. Biochemistry Journal, London, v.57, p.508-514, 1954. 